\title{
Surgical Strategies for Epilepsy in Eloquent Areas
}

\section{John D Rolston*}

Department of Neurological Surgery, University of California, San Francisco, CA, USA

\begin{abstract}
Patients with medically refractory epilepsy should be evaluated for potentially curative epilepsy surgery when feasible. However, if seizure foci occur in eloquent brain regions-regions where damage causes overt neurological deficits-alternative treatments must be considered. This review will discuss what defines eloquent cortex, and the various treatments of seizure foci in eloquent regions, including resective surgery, multiple subpial transections, electrical brain stimulation of the anterior nucleus of the thalamus, closed-loop responsive neurostimulation, and vagus nerve stimulation.
\end{abstract}

Keywords: Refractory epilepsy; Seizures; Eloquent; Palliative; Extratemporal lobe epilepsy

\section{Introduction}

Medically refractory epilepsy is diagnosed after a patient fails two adequate trials of antiepileptic drugs [1]. Adding further drugs has a low likelihood of providing additional benefit $(<5 \%)$, and patients should be referred to a comprehensive epilepsy center for surgical evaluation [2].

As part of their initial workup, patients typically undergo videoelectroencephalography (video-EEG), magnetic resonance imaging (MRI) of the brain, and neuropsychological testing [3]. Depending on how well these tests localize the epileptic foci, additional studies might be indicated, such as positron emission tomography (PET), magnetoencephalography (MEG), and single photon-emission computed tomography (SPECT).

Extraoperative electrocorticography (ECoG), where electrodes are placed either cortically (with electrode grids and strips) or subcortically (with depth electrodes), is used to further refine the anatomic location of epileptic foci when prior studies are discordant or insufficiently detailed [4]. Bypassing the skull and scalp allows these electrodes to have greater spatial and temporal precision in detecting epileptic activity, since those tissues act as filters which degrade the normal EEG. In particular, if there is concern that seizure foci are localized within or near eloquent areas; ECoG can help identify safe margins of resection.

\section{What is eloquent brain?}

Eloquent regions are loosely defined as anatomical brain areas where damage causes overt, disabling symptoms, such as language areas or primary motor cortex. Nevertheless, specific eloquent brain areas are often implicitly rather than explicitly defined. Robert Spetzler and Neil Martin proposed perhaps the most well-known delimited anatomical grouping of eloquent regions as part of their rating scale for evaluating arteriovenous malformations (AVMs) [5]. In their rating scale, eloquent regions were limited to "sensorimotor, language, and visual cortex; the hypothalamus and thalamus; the internal capsule; the brain stem; the cerebellar peduncles; and the deep cerebellar nuclei." All other regions were considered non-eloquent. The exclusion of the basal ganglia is an obvious omission, since damage to these structures can cause overt neurological deficits, and the inclusion of sensory cortex is somewhat conservative, given how patients will often tolerate sensory loss in return for treatment of tumors, vascular lesions, or epileptic foci. The Spetzler and Martin definition of eloquent cortex also disregards subtler neurological abilities of other cortical regions, such as memory, attention, and executive function. For example, while the hippocampus is not considered eloquent by Spetzler and Martin, indiscriminate hippocampal damage can be uniquely devastating (e.g., patient HM [6]), as can damage to the orbitofrontal cortex (Phineas Gage [7]) and amygdalae (patient SM [8]).

Ultimately, what constitutes eloquent cortex is best determined by detailed neuropsychological testing and discussions with the patient. For example, some patients are willing to risk visual field deficits for the chance of a cure, while others will find even the slightest risk of a quadrantanopia unacceptable. Other patients will draw similar "red lines" at memory, sensory, and language deficits.

\section{Surgical resection}

Assuming both the seizure focus and eloquent cortex have been defined, surgical resection is a valid option if there is clear separation between the two regions. Close proximity of the epileptic focus and eloquent areas benefits from careful and detailed functional mapping. This will likely require extra-operative ECoG as a means to tightly define the seizure onset zone for resection [4]. ECoG will also permit preoperative motor, language, and sensory mapping, highlighting areas of the epileptic focus that are free of eloquent function.

Even if extra-operative mapping is used, intraoperative mapping is still indicated and can provide useful additional information. Motor mapping can be done with the patient under general or monitored (conscious) anesthesia, though language mapping always requires awake surgical techniques [9]. Awake motor mapping is generally considered better able to preserve function, though is sometimes impractical for young patients or patients otherwise unable to cooperate with detailed motor testing. Using a handheld stimulator (e.g., the Ojemann stimulator) will allow an unlimited number of test points for mapping, compared to the pre-specified points of the extraoperative ECoG grid, helping to maximize the area of safe resection.

Mapping of higher-level functions, like verbal memory, is less straight-forward and cannot currently be done with electrical

*Corresponding author: John D Rolston, Department of Neurological Surgery, University of California, San Francisco, CA, USA, Tel: 415-353 3904; E-mail: John.Rolston@ucsf.edu

Received November 04, 2015; Accepted December 28, 2015; Published January 08, 2016

Citation: Rolston JD (2016) Surgical Strategies for Epilepsy in Eloquent Areas. J Epilepsy 2: 103. doi:10.4172/2472-0895.1000103

Copyright: (c) 2016 Rolston JD. This is an open-access article distributed under the terms of the Creative Commons Attribution License, which permits unrestricted use, distribution, and reproduction in any medium, provided the original author and source are credited. 
stimulation intraoperatively. Determining the location of regions of higher-level eloquence is less anatomically precise and relies on preoperative techniques like the Wada test, functional MRI (fMRI), and transcranial magnetic stimulation (TMS) [10-13].

After detailed mapping, seizure foci are sometimes found directly within eloquent regions, or too close for safe resection. For these cases, a variety of non-destructive techniques have been devised, which will be described below (Table 1).

\section{Multiple subpial transections}

Multiple subpial transection (MST) was first described by Frank Morrell and colleagues in 1989 [14]. The rationale was founded on the columnar organization of the cortex, as described by Vernon Mountcastle and others, which posits that vertical columns of neurons are the functional unit of the neocortex [15]. Severing the connections between these columns, but leaving the columns themselves intact, was hypothesized by Morrell to retain neurological function but prevent the spread of seizures by preventing aberrant synchronization between nearby areas.

The original technique used a thin stainless steel wire with the last 4 $\mathrm{mm}$ bent at a right angle [14]. The wire was inserted under a gyrus and the bent tip then raised orthogonally to the pial surface. The wire was then dragged across the gyrus, with the hook severing corticocortical connections within the cortical layers. Subcortical white matter was minimally affected.

Morrell et al. originally reported on 32 patients, where MST was used in primary motor cortex, primary sensory cortex, Broca's area, and Wernicke's area [14]. They had 5-year follow-up in 20 cases, and reported seizure freedom in 55\%. No complications and no new neurological deficits were noted. Unfortunately, nearly all of these MST patients also underwent simultaneous surgical resection of noneloquent epileptic areas. So there is no clear way to ascribe these benefits to MST vs. standard surgical resection. That is, we are unable to assess what additional benefit was conferred by MST over resection alone.

Numerous other studies went on to further investigate the risks and benefits of MST, along with disentangling the relative contributions of MST over unadorned surgical resection. The most recent meta-analysis by Spencer et al. showed excellent outcome ( $>95 \%$ reduction in seizure frequency) for isolated MST without resection in $62-71 \%$ of patients, depending on the seizure subtype [16]. When MST was combined with

\begin{tabular}{|l|l|l|l|}
\hline Treatment & $\begin{array}{l}\text { Reversible/ } \\
\text { Irreversible? }\end{array}$ & Advantages & Disadvantages \\
\hline Resection & Irreversible & $\begin{array}{l}\text { Potentially definitive } \\
\text { cure if isolated focus } \\
\text { identified }\end{array}$ & $\begin{array}{l}\text { Highest risk of } \\
\text { permanent neurologic } \\
\text { deficit }\end{array}$ \\
\hline MST & Irreversible & $\begin{array}{l}\text { Potentially lower } \\
\text { risk to neurological } \\
\text { function than } \\
\text { resection }\end{array}$ & $\begin{array}{l}\text { Not as effective as } \\
\text { resection when used } \\
\text { alone; can still lead to } \\
\text { permanent neurologic } \\
\text { deficit }\end{array}$ \\
\hline $\begin{array}{l}\text { Electrical } \\
\text { stimulation } \\
\text { (DBS or RNS) }\end{array}$ & Reversible & $\begin{array}{l}\text { Programmable } \\
\text { with low likelihood } \\
\text { of neurologic } \\
\text { impairment }\end{array}$ & $\begin{array}{l}\text { Requires periodic } \\
\text { battery changes; newer } \\
\text { and less-studied than } \\
\text { surgical resection; very } \\
\text { low chance of cure }\end{array}$ \\
\hline VNS & Reversible & $\begin{array}{l}\text { Entirely extra-cranial; } \\
\text { no direct risk to brain } \\
\text { tissue }\end{array}$ & $\begin{array}{l}\text { Requires periodic } \\
\text { battery changes; can } \\
\text { achieve a reduction in } \\
\text { seizures, but very low } \\
\text { chance of cure }\end{array}$ \\
\hline
\end{tabular}

Table 1: Comparison of treatments for eloquent seizure foci. resection, the rates were better: $68-87 \%$. New neurological deficits were observed in $19 \%$ of patients with isolated MST and $23 \%$ of patients with combined resection and MST [16].

\section{Cortical and subcortical neurostimulation}

Direct electrical stimulation of the brain, whether cortical or subcortical, is one of the most recently developed options for treating eloquent seizure foci. The two leading methods are deep brain stimulation (DBS) of the anterior nucleus of the thalamus (ANT) $[17,18]$ and responsive neurostimulation (RNS) of epileptic foci [19]. ANT DBS is an open-loop stimulation paradigm, similar to DBS for movement disorders like Parkinson's disease, essential tremor, and dystonia. Briefly, a stimulation electrode with four contacts is stereotactically placed within the ANT and connected to an implanted pulse generator (IPG), which is typically placed in the patient's chest. The thalamic target is then stimulated continuously in an effort to modulate the epileptogenic network and reduce the frequency of seizures. The anterior nucleus was chosen based on its modulatory presence in the limbic circuit of Papez.

The RNS system, produced by the company NeuroPace (Mountain View, CA, USA), is a closed-loop system where recorded electrical ECoG activity is used to trigger stimulation in an effort to terminate seizures as they begin [20,21]. The completely implantable system is flexible in that either depth electrodes (like those used in DBS) or ECoG strips, or a combination of both, can be used for recording and stimulation. The stimulating electrodes are therefore cortical or subcortical depending on the patient's individual epileptic focus location. Seizure detection parameters and stimulation parameters are programmed over the course of several months (and sometimes years) following the device implant. Unlike DBS, the pulse generator is implanted in the skull itself, rather than distally in the chest.

Randomized clinical trials (RCTs) have been completed for both ANT DBS and RNS, and both showed positive results [21]. For RNS, seizures were reduced by $37.9 \%$ at the end of the 12 -week blinded evaluation phase of the RCT [19], $44 \%$ at 1 -year, and $53 \%$ at 2 -years [22], showing a gradual increase in efficacy (though this follow-up data is unblinded). Similarly, ANT DBS showed a $40.4 \%$ decrease in seizure frequency at the end of the RCT's 3-month blinded phase [18], followed by a $69 \%$ decrease at 5 -year, open-label follow-up [23]. Neither device has been examined for purely eloquent foci epilepsy, so results must be extrapolated for this indication. However, the reversibility-and thereby safety-of both procedures is an advantage compared to MST or resection.

\section{Vagus nerve stimulation}

An alternative to the above modalities is vagus nerve stimulation (VNS), which is unique in being entirely extra-cranial, as compared to surgical resection, MST, or direct electrical stimulation of the brain [21]. In VNS, a stimulating electrode is coiled around the patient's vagus nerve within the neck (usually the left side) and connected to an IPG (typically placed within the chest, as in DBS). The device then stimulates the vagus nerve intermittently in an effort to modulate epileptogenic activity and reduce the frequency of seizures, similar to DBS of the ANT. The mechanisms are unknown, but presumed to act through neuromodulatory effects emanating from the brainstem [24].

Two large randomized clinical trials found a response of $23 \%$ [25] and $31 \%$ [26] of patients achieving a $>50 \%$ reduction in seizures. Many other studies (though all retrospective or Class II-III) have shown better results, with a meta-analysis showing $\sim 50 \%$ of patients experiencing a $>50 \%$ reduction in seizures at long-term follow-up [27]. Of note, none 
of these studies specifically addresses VNS for use in seizures with eloquent foci, so the results in such patients must be extrapolated from the use of VNS in other indications.

Complications with VNS are common but usually mild. For example, hoarseness in $37-62 \%$ of patients, cough in $7-21 \%$, and parasthesias in 6-25\% [25-28].

\section{Discussion}

For patients with refractory medical epilepsy, surgical resection offers the best hope for a potential cure. Unfortunately, if the seizure foci are located within eloquent cortex, resection might not be an option. In these cases, careful electrical stimulation mapping and neuropsychological studies are required to pinpoint the exact bounds of eloquent cortex and seizure foci. Safely resectable cortex should continue to be removed, leaving only truly eloquent cortex behind. For these remaining epileptogenic regions, options include MST, electrical stimulation of the brain, and VNS. MST has several studies showing its safety and utility in eloquent cortex, but is nevertheless higher risk than reversible procedures like DBS, RNS, or VNS [21]. No direct comparisons between these alternative treatments are available, so it is unknown if one is better than another. Moreover, none have been directly examined with regard specifically to eloquent cortex, while MST has. More research is clearly needed to address the comparative utility of these techniques for eloquent cortex. For patients, though, the choice will be an individual one, taking into account patient preferences for reversibility and risk tolerance.

\section{References}

1. Kwan P, Arzimanoglou A, Berg AT, Brodie MJ, Allen Hauser W, et al. (2010) Definition of drug resistant epilepsy: consensus proposal by the ad hoc Task Force of the ILAE Commission on Therapeutic Strategies. Epilepsia 51: 1069 1077.

2. Kwan P, Brodie MJ (2000) Early identification of refractory epilepsy. N Engl J Med 342: 314-319

3. Rathore C, Radhakrishnan K (2015) Concept of epilepsy surgery and presurgical evaluation. Epileptic Disorders 17: 19-31.

4. Fernández IS, Loddenkemper T (2013) Electrocorticography for seizure foci mapping in epilepsy surgery. J Clin Neurophysiol 30: 554-570.

5. Spetzler RF, Martin NA (1986) A proposed grading system for arteriovenous malformations. J Neurosurg 65: 476-483.

6. Scoville WB, Milner B (1957) Loss of recent memory after bilateral hippocampal lesions. J Neurol Neurosurg Psychiatr 20: 11-21.

7. Harlow JM (1993) Recovery from the passage of an iron bar through the head. History of Psychiatry 4: 274-281.

8. Bechara A, Tranel D, Damasio H, Adolphs R, Rockland C, et al. (1995) Double dissociation of conditioning and declarative knowledge relative to the amygdala and hippocampus in humans. Science 269: 1115-1118.

9. Kilbride RD (2013) Intraoperative Functional Cortical Mapping of Language. Journal of Clinical Neurophysiology 30: 591-596.

10. Akanuma N, Koutroumanidis M, Adachi N, Alarcón G, Binnie CD (2003) Presurgical assessment of memory-related brain structures: the Wada test and functional neuroimaging. Seizure 12: 346-358.

11. Bauer PR, Reitsma JB, Houweling BM, Ferrier CH, Ramsey NF (2014) Can fMRI safely replace the Wada test for preoperative assessment of language lateralisation? A meta-analysis and systematic review. J Neurol Neurosurg Psychiatr 85: 581-588.

12. Baxendale S (2009) The Wada test. Curr Opin Neurol 22: 185-189.

13. Kimiskidis VK, Valentin A, Kälviäinen R (2014) Transcranial magnetic stimulation for the diagnosis and treatment of epilepsy. Curr Opin Neurol 27 236-241.
14. Morrell F, Whisler WW, Bleck TP (1989) Multiple subpial transection: a new approach to the surgical treatment of focal epilepsy. J Neurosurg 70: 231-239.

15. Mountcastle VB (1998) Perceptual Neuroscience. Harvard University Press, USA.

16. Spencer SS, Schramm J, Wyler A, O'Connor M, Orbach D, et al. (2002) Multiple Subpial Transection for Intractable Partial Epilepsy: An International Meta-analysis. Epilepsia 43: 141-145.

17. Salanova V, Witt T, Worth R, Henry TR, Gross RE, et al. (2015) Long-term efficacy and safety of thalamic stimulation for drug-resistant partial epilepsy. Neurology 84: 1017-1025.

18. Fisher R, Salanova V, Witt T, Worth R, Henry T, et al. (2010) Electrical stimulation of the anterior nucleus of thalamus for treatment of refractory epilepsy. Epilepsia 51: 899-908.

19. Morrell MJ (2011) RNS System in Epilepsy Study Group. Responsive cortical stimulation for the treatment of medically intractable partial epilepsy. Neurology 77: 1295-1304.

20. Liu C, Wen XW, Ge Y, Chen N, Hu W-H, et al. (2013) Brain Research Bulletin. Brain Research Bulletin 97: 39-47.

21. Rolston JD, Englot DJ, Wang DD, Shih T, Chang EF (2012) Comparison of seizure control outcomes and the safety of vagus nerve, thalamic deep brain, and responsive neurostimulation: evidence from randomized controlled trials Neurosurg Focus 32: E14.

22. Bergey GK, Morrell MJ, Mizrahi EM, Goldman A, King-Stephens D, et al. (2015) Long-term treatment with responsive brain stimulation in adults with refractory partial seizures. Neurology 84: 810-817.

23. Salanova V, Witt T, Worth R, Henry TR, Gross RE, et al. (2015) Long-term efficacy and safety of thalamic stimulation for drug-resistant partial epilepsy. Neurology 84: 1017-1025.

24. Lulic D, Ahmadian A, Baaj AA, Benbadis SR, Vale FL (2009) Vagus nerve stimulation. Neurosurg Focus 27: E5.

25. Handforth A, DeGiorgio CM, Schachter SC, Uthman BM, Naritoku DK, et al. (1998) Vagus nerve stimulation therapy for partial-onset seizures: a randomized active-control trial. Neurology 51: 48-55.

26. Ben-Menachem E, Mañon Espaillat R, Ristanovic R, Wilder BJ, Stefan $H$ et al. (1994) Vagus Nerve Stimulation for Treatment of Partial Seizures: 1. A Controlled Study of Effect on Seizures. Epilepsia 35: 616-626.

27. Englot DJ, Chang EF, Auguste KI (2011) Vagus nerve stimulation for epilepsy: a meta-analysis of efficacy and predictors of response. J Neurosurg 115: 1248 1255.

28. DeGiorgio C, Heck C, Bunch S, Britton J, Green P (2005) Vagus nerve stimulation for epilepsy: randomized comparison of three stimulation paradigms. Neurology 65: 317-319. 